Available online on 15.01.2020 at http://jddtonline.info
Open Access to Pharmaceutical and Medical Research
unrestricted non-commercial use, provided the original work is properly cited

Open $\odot$ Access

Review Article

\title{
Tirosyne Kinase Inhibithors (TKIs) in the Treatment of Non -Small Cell Lung Cancer (NSCLC), Practical Pharmacological Aspects
}

\author{
Alexandru C. Grigorescu ${ }^{1 *}$, Laura Mihaela Teodorescu ${ }^{2}$ \\ 1 The Oncological Institute of Bucharest, 252 Sos. Fundeni, Bucuresti, Romania \\ ${ }^{2}$ V. Babes Diagnostic and Treatment Center, 281 Sos M. Bravu, 143308 Bucharest, Romania
}

\begin{abstract}
Tyrosine Kinase Inhibitors are new drugs developed in the last decade. For Non-Small Cell Lung Cancer this drug brought more hope for patients with this disease. Also TKIs are better tolerated then chemotherapy. The efficacy of TKIs is dependent of the presence of Epidermal Grows Factor Receptor gene mutation. This mutation account for about $9 \%$ of patients with lung cancer in Europe. This short review try to give the minimal knowledge to clinicians, especially medical oncologists, about mechanism of action, pharmacokinetics of TKIs used in the treatment NSCLC.
\end{abstract}

Keywords: Tyrosine Kinase Inhibitors (TKI); Non -Small Cell Lung Cancer; Pharmacokinetics aspects

Article Info: Received 12 Nov 2019; $\quad$ Review Completed 20 Dec 2019; $\quad$ Accepted 28 Dec 2019; Available online 15 Jan 2020

Cite this article as:

Grigorescu AC, Teodorescu LM, Tirosyne Kinase Inhibithors (TKIs) in the Treatment of Non -Small Cell Lung Cancer (NSCLC), Practical Pharmacological Aspects, Journal of Drug Delivery and Therapeutics. 2020; 10(1):135-138 http://dx.doi.org/10.22270/jddt.v10i1.3830

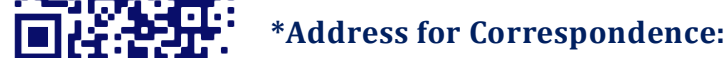

Alexandru C. Grigorescu, The Oncological Institute of Bucharest, 252 Sos. Fundeni, Bucuresti, Romania

\section{Introduction}

Non-small cell lung cancer (NSCLC) causes the highest cancer mortality in the world. In 2018, there were 2 million new cases worldwide. In the first 3 places regarding the incidence of NSCLC in the world in 2018 were: Hungary 56.7 / 100,000, Serbia 49.8 / 100,000 and New Caledonia (France) 42.3 / 100,000. In Romania, the mortality due to lung cancer was $37.7 / 100,000$ in 2017.1 One of the therapeutic advances in this true scourge, represented by NSCLC, is tyrosine kinase inhibitors (TKIs). Tyrosine kinases are enzymes responsible for so-called cascade activation of many proteins through signal transduction. Proteins are activated by phosphorylation, a step that TKIs inhibit. TKIs are commonly used in cancer therapy. ${ }^{2}$

Prior to the introduction of TKIs in NSCLC therapy, platinum salt combination chemotherapy resulted in overall survival (OS) for many patients with NSCLC less than one year. ${ }^{3}$ With the introduction of EGFR inhibitors represented by TKIs, the therapeutic approach of NSCLC has changed by taking into account when establishing the therapeutic conduct of both histology and genetic determinations appearing in so-called "targeted therapies". 4

The chemical formulas of the main TKIs are presented below $5:$<smiles>C#Cc1cccc(Nc2ncnc3cc(OCCOC)c(OCCOC)cc23)c1</smiles>

1. Erlotinib (First generation TKIs)<smiles>C=CC(=O)Nc1cc(Nc2nccc(-c3cn(C)c4ccccc34)n2)c(OC)cc1N(C)CCN(C)C</smiles>

2. Osimertinib (Thread generation TKIs<smiles>CN(C)C/C=C/C(=O)Nc1cc2c(Nc3ccc(F)c(Cl)c3)ncnc2cc1OC1CCOC1</smiles>

3. Afatinib (Second generation TKIs) 


\section{The mechanism of molecular action}

EGFR, also called ErbB1, is part of the ErB family. There are 4 receptors described as tyrosine kinase receptors. Other members of this receptor family include ErbB2 (HER2), ErbB3 (HER3) and ErbB4 (HER4). The structure of these receptors is the commune that comprises an extracellular ligand binding domain, a transmembrane domain and an intracellular domain that has tyrosine kinase activity for signal transduction. Binding of its ligand to EGFR initiates an intracellular signaling cascade that ultimately leads to cell proliferation and results in cell survival 6 .

All EGFR-TKI have a similar high affinity for the EGFR receptor ${ }^{7-9}$ Afatinib and dacomitinib also have a high affinity for the HER2 and HER4 receptors. Afatinib also inhibits HER3 transphosphorylation, thereby blocking the signaling of all members of the ErbB family.10 In vitro, all tyrosine kinase inhibitors cause inhibition of proliferation of NSCLC cell lines expressing L858R EGFR or L858R / T790M EGFR mutations, with lower activity against wild-type EGFR lines. ${ }^{11}$

\section{Pharmacokinetics}

As this review is addressed to clinicians, we will discuss only a few practical aspects of TKIs pharmacokinetics used in advanced NSCLC.

From the point of view of the administration of these drugs, the researchers pointed out that Gefitinib could be taken without regard to food intake, because bioavailability is not influenced by food. In contrast, food intake concomitantly with Dasatinib and Erlotinib increases bioavailability. For the mentioned TKIs, the primary enzyme in their metabolism is CYP3A4. The major metabolites of

Dasatinib are 4 (BMS-582691), M5 (BMS-606181), M6 (BMS573188), for erlotinib is NorErlotinib (OSI-420) and for Gefitinib NorGefitinib (M523595).12

Oral absorption of EGFR TKIs is slow to moderate and has significant variability both within the same individual and from one individual to another. Plasma concentrations of gefitinib are obtained 3-7 hours after administration to healthy subjects and patients with solid tumors. ${ }^{13}$ The solubility of these compounds at high pH is limited [14] and in this case co-administration of drugs that increase gastric $\mathrm{pH}$, such as histamine $\mathrm{H} 2$ receptor antagonists and proton pump inhibitors may lead to decreased absorption and bioavailability. Similar effects may have high doses of shortacting antacids if taken regularly around the time of taking gefitinib. ${ }^{14}$ Erlotinib has absorption characteristics similar to those of gefitinib. However, as food increases bioavailability (from $60 \%$ to almost $100 \%$ ), erlotinib should be given at least one hour before or two hours after eating. 15 Afatinib reaches peak plasma concentrations 2-5 hours after oral administration in patients with solid tumors. The absolute bioavailability of afatinib is not known. ${ }^{16}$. Foods have a moderate influence on the absorption of afatinib, and therefore patients should take afatinib at least $1 \mathrm{~h}$ before or 2-3 hours after meal.

It has been established that Dacomitinib has a good oral bioavailability (80\%) after a dose of $45 \mathrm{mg}$ and its concentration after administration behaves after linear kinetics after single or multiple doses. ${ }^{17-18}$ Foods have only a slight, negligible effect (data for dacomitinib indicate that food intake has no effect on bioavailability) on absorption, but co-administration with antacid medication should be avoided. For the other EGFR TKIs, interindividual variability is high (coefficient of variation up to $50 \%$ ). ${ }^{19}$ In summary, gefitinib, erlotinib, afatinib and dacomitinib demonstrate significant interindividual variability in drug uptake.

The distribution of EGFR TKIs is characterized by an extensive tissue distribution and moderate binding of plasma proteins to the sea, ranging from $90 \%$ for gefitinib to $97-$ $98 \%$ for dacomitinib, dacomitinib is excreted as both a parent compound and metabolites.. ${ }^{20-21}$ The half-life is generally extended (2-3 days) in patients with cancer but for erlotinib (36 h) 22 and afatinib (37 h) the half-life is shorter. ${ }^{24}$

Metabolism is slightly different, so unlike afatinib, gefitinib, erlotinib, dacomitinib undergoes extensive hepatic metabolism predominantly by cytochrome P450 (CYP) dependent enzymes. Gefitinib is metabolised by CYP3A4 and, to a lesser extent, by CYP2D6 and CYP3A5.25,26 Erlotinib is metabolized by CYP3A4 / 3A5 and, to a lesser extent, by CYP1A1 / 1A2 isoenzymes, to the active metabolite desmethyl erlotinib, which subsequently enter into an oxidation and glucuronidation process. Extra-hepatic metabolism is achieved by CYP3A4 in the intestine, CYP1A1 in the lung and in tumor tissue where CYP1B1 also contributes to metabolic elimination of erlotinib. It is known that cigarette smoking induces CYP enzymes which is a key enzyme. Currently studies have shown that induction of CYP1A1 / 1A2 in smokers results in increased metabolism and clearance of erlotinib which subsequently leads to a reduction in exposure after a standard therapeutic dose. $27,28,29$

Dacomitinib is metabolized by oxidation process and conjugation with glutathione involving CYP2D6 and CYP3A4, resulting in the active metabolite 0 -des methyl dacomitinib having in vitro activity similar to the parent compound. ${ }^{30}$ In contrast, afatinib undergoes minimal biotransformation, and CYP-mediated oxidant metabolism is negligible. ${ }^{31}$

Osimertinib, a third-generation tyrosine kinase (TKI) inhibitor, undergoes significant hepatic elimination. No apparent differences in the safety of osimertinib administration were found between patients with normal liver function and those with mild or moderate hepatic impairment. ${ }^{32}$

Administration of oral osimertinib once daily resulted in accumulation with steady state exposure after 15 days of administration. In the constant state, the ratio Cmax (maximum concentration) to Cmin (minimum concentration) was 1.6. After absorption, the mean time to Cmax of osimertinib was 6 hours (range 3-24 hours). The mean volume of distribution of osimertinib at steady state (Vss / F) was $918 \mathrm{~L}$. The plasma protein binding of osimertinib was 95\%. E Osimertinib plasma concentrations decreased with elimination time and an estimated half-life of osimertinib was 48 hours and oral clearance (CL / F) was 14.3 (L/h). .

The main in vitro metabolic pathways of osimertinib were oxidation (predominantly CYP3A) and dealkylation. Two pharmacologically active metabolites (AZ7550 and AZ5104) were identified in plasma after oral administration of osimertinib. Osimertinib is eliminated mainly in the faeces $(68 \%)$ and in the urine to a lesser extent $(14 \%))^{33}$

\section{Benefits of treatment with TKIs in NSCLC}

The first generation of EGFR TKIs, gefitinib and erlotinib, act by reversibly and competitively inhibiting the EGFR tyrosine kinase domain. Both gefitinib and erlotinib have shown in studies that have resulted in significant improvements in response rate, progression-free survival (PFS) and quality of life (QOL) compared with chemotherapy in the selected population of NSCLC patients with EGFR mutation (3-5). So far, it has not been shown in any of these studies that there is 
a benefit in overall survival (OS). This may be due to crossover treatments and the relatively high efficacy of chemotherapy in this type of lung cancer. In addition, the toxicity was comparable for gefitinib and erlotinib. The difference from second-generation TKIs is that the latter, namely afatinib and dacomitinib, are irreversible covalent inhibitors of EGFR.

Afatinib and dacomitinib also inhibited other members of the epidermal growth factor (HER) receptor family (pan-HER inhibitors). Consequently, both dacomitinib and afatinib also have a certain therapeutic value in NSCLC with driver mutation of HER2.34,35,36 The Lux-Lung Phase IIb study 7 was the first to compare a second-generation EGFR TKI (afatinib) with a first-generation EGFR TKI (gefitinib) in first-line treatment for NSCLC harboring an activating EGFR mutation . In this study, afatinib resulted in an improvement of statistically significant progression free survival and time-totreatment failure. ${ }^{37}$

More recently, Wu et al published the results of the ARCHER 1050 study, recently published in Lancet Oncol. It is a phase III study comparing dacomitinib versus gefitinib in the first line treatment. In this study, dacomitinib significantly improved PFS from 9.2 to 14.7 months (HR: 0.59 and P $<0.0001$ ) compared to gefitinib. Data on overal survival are immature. In this study, treatment with dacomitinib had an increased toxicity of grade $3 / 4$. Toxicity has often required dose reduction. Dacomitinib is thus the first EGFR TKI that has demonstrated statistically significant and clinically significant superior activity in PFS compared to gefitinib, a first-generation TKI. However, given the increased toxicity, more data will be needed on the clinical benefits and impact of dacomitinib treatment on quality of life. ${ }^{38}$

Osimertinib is a third generation of TKIs that irreversibly blocks the EGFR receptor. This third generation TKI selectively inhibits both EGFR/ TKI sensitizing mutation and EGFR /T790M resistance mutations. This compound has a lower activity against the wild type EGFR and is in fact, in the United States, the standard first-line treatment for patients with locally advanced or metastatic NSCLC with an epidermal growth factor receptor (EGFR) mutation. The FDA decision was made after the publication of positive overall survival (OS) results from the Phase III FLAURA study. This study was a randomized, double-blind, multi-center study with osimertinib in first-line treatment for patients with locally advanced or metastatic NSCLC with EGFR mutations. 39,40

\section{Conclusions}

In summary, the EGFR-TKIs offer a targeted therapeutic approach to the management of NSCLC. Review of the pharmacokinetics of gefitinib, erlotinib, afatinib , dacomitinib end osimertinib highlight differences in absorption and/or metabolism which influence their potential for drug-drug interactions, highly relevant in the setting of polymedicated cancer patients. In routine clinical practice, afatinib may offer a number of theoretical advantages, notably lack of CYPrelated interaction potential as well as with acid-reducing agents $\left(\mathrm{H}_{2}\right.$-receptor antagonists, proton-pump inhibitors and antacids).

The first line therapy, for NSCLC with EGFR mutation, is in the latest evidence in favor of osimertinib. However clinicians should evaluate the patient condition and co morbidities in order to choose the best first line treatment.

\section{References}

1.https://www.wcrf.org/dietandcancer/cancer-trends/lung-cancerstatistics

2. https://en.wikipedia.org/wiki/Tyrosine_kinase_inhibitor

3. https://www.who.int/cancer/country.../rou_en.pdf

4. Ciardiello, F. and Tortora, G. EGFR antagonists in cancer treatment. N Engl J Med. 2008; 358: 1160-1174

5.https://www.google.com/search?q=tki+pharmacology+chemical+f ormula\&tbm=isch \&source $=$ univ\&sa $=X \& v e d=2 a h U K E w i M p b 7 F j 4$ fkAhUDIYsKHbW-DxkQsAR6BAgJEAE\&biw=1138\&bih=512

6. Foluso Ogunleye, MD; Mohammed Ibrahim, MD; Michael Stender, MD; Gregory Kalemkerian, MD; Ishmael Jaiyesimi, Epidermal Growth Factor Receptor Tyrosine Kinase Inhibitors in Advanced Non-Small Cell Lung Cancer A paradigm shift in stage IV nonsmall cell lung cancer treatment

https://www.gotoper.com/publications/ajho/2015/2015jan/e pidermal-growth-factor-receptor-tyrosine-kinase-inhibitors-inadvanced-non-small-cell-lung-cancer

[7] Kitagawa D, Yokota K, Gouda M, et al. Activity-based kinase profiling ofapproved tyrosine kinase inhibitors. Genes Cells 2013;18:110-22.

[8] Li D, Ambrogio L, Shimamura T, et al. BIBW2992, an irreversible EGFR/HER2inhibitor highly effective in preclinical lung cancer models. Oncogene2008;27:4702-11.

[9] Solca F, Dahl G, Zoephel A, et al. Target binding properties and cellular activityof afatinib (BIBW 2992), an irreversible ErbB family blocker. J Pharmacol ExpTher 2012;343:342-50.

[10]Engelman JA, Zejnullahu K, Gale CM, et al. PF00299804, an irreversible pan-ERBB inhibitor, is effective in lung cancer models with EGFR and ERBB2mutations that are resistant to gefitinib. Cancer Res 2007;67:11924-32.

11. Solange Petersa, Stefan Zimmermanna, Alex A. Adjeib, Ora epidermal growth factor receptor tyrosine kinase inhibitors for the treatment of non-small cell lung cancer: comparative pharmacokinetics and drug-drug interactions. Cancer Treat Rev. 2014 Sep;40(8):917-26. doi: 10.1016/j.ctrv.2014.06.010.

12. Niels Eckstein, Lea Röper, Bodo Haas, Henrike Potthast, Ulrike Hermes, Christoph Unkrig, ${ }^{1}$ Frauke Naumann-Winter, ${ }^{1}$ and Harald Enzmann ${ }^{1}$, Clinical pharmacology of tyrosine kinase inhibitors becoming generic drugs: the regulatory perspective, doi: 10.1186/1756-9966-33-15, J Exp Clin Cancer Res. 2014; 33(1): 15.

13. Swaisland H, Laight A, Stafford L, et al. Pharmacokinetics and tolerability of the orally active selective epidermal growth factor receptor tyrosine kinase inhibitor ZD1839 in healthy volunteers, Clin Pharmacokinet, 40 (2001), 297-306

14. Swaisland HC, Smith RP, Laight A, et al. Single-dose clinical pharmacokinetic studies of European Medicines Agency. Iressa (gefitinib) Assessment Report, July 2009. http://www.ema.europa.eu/docs/en_GB/document_library/EP AR_-

_Public_assessment_report/human/001016/WC500036361.pdf 20022014.

15. Frohna P, Lu J, Eppler S, et al.Evaluation of the absolute oral bioavailability and bioequivalence of erlotinib, an inhibitor of the epidermal growth factor receptor tyrosine kinase, in a randomized, crossover study in healthy subjects,J Clin Pharmacol, 46 (2006), pp. 282-290

16 Boehringer Ingelheim. Gilotrif [prescribing information] (2014) Boehringer Ingelheim Pharmaceuticals, Inc., Ridgefield, CT. http://www.gilotrif.com/. 17052014.

17. Giri N, LaBadie RR, Liang Y, et al. Absolute bioavailability of dacomitinib (PF-00299804): Comparison of oral and intravenous administration in healthy volunteers. Proceedings of the 105th Annual Meeting of the American Association for 
Cancer Research; 2014 Apr 5-9; San Diego, CA. Philadelphia (PA): Abstract CT208.

18. Jänne PA, Boss DS, Camidge DR, et al. Phase I dose-escalation study of the pan-HER inhibitor, PF299804, in patients with advanced malignant solid tumors, Clin Cancer Res, 17 (2011), 1131-1139

19. Ruiz-Garcia A, Masters JC, LaBadie RR, et al.Effect of food and antacid treatment on bioavailability of $45 \mathrm{mg}$ tablet of dacomitinib relative to dacomitinib administration under fasted conditions (abstract PII-007),Clin Pharmacol Ther, 95 (2014), S63

20. European Medicines Agency. Giotrif. Summary of Product

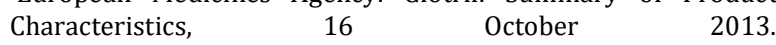
http://www.ema.europa.eu/docs/en_GB/document_library/EP AR_Product_Information/human/002280/WC500152392.pdf. 2002 2014].

21. Bello, C.L., Smith, E., Ruiz-Garcia, A. et al. A phase I, open-label, mass balance study of $\left[{ }^{14} \mathrm{C}\right]$ dacomitinib (PF-00299804) in healthy male volunteers. Cancer Chemother Pharmacol. 2013; 72: $379-385$

22.Lu, J.F., Eppler, S.M., Wolf, J. et al. Clinical pharmacokinetics of erlotinib in patients with solid tumors and exposure-safety relationship in patients with non-small cell lung cancer. Clin Pharmacol Ther. 2006; 80: 136-145|

24.Schnell D, Buschke S, Fuchs H, et al. Pharmacokinetics of afatinib in subjects with mild or moderate hepatic impairment. Cancer Chemother Pharmacol 2014; Jun 7. [Epub ahead of print].

25. D. McKillop, A.D. McCormick, A. Millar, et al.Cytochrome P450dependent metabolism of gefitinib Xenobiotica, 35 (2005), 3950

26. H.C. Swaisland, R.P. Smith, A. Laight, et al.Single-dose clinical pharmacokinetic studies of gefitinib, Clin Pharmacokinet, 44 (2005),1165-1177

27. J. Ling, K.A. Johnson, Z. Miao, et al.Metabolism and excretion of erlotinib, a small molecule inhibitor of epidermal growth factor receptor tyrosine kinase, in healthy male volunteers Drug Metab Dispos, 34 (2006),420-426

28. Li J, Zhao M, He P, Hidalgo M, Baker SD, Differential metabolism of gefitinib and erlotinib by human cytochrome P450 enzymes, Clin Cancer Res, 13 (2007) 3731-3737

29. Hamilton M, Wolf JL, Rusk J, et al.Effects of smoking on the pharmacokinetics of erlotinib Clin Cancer Res, 12 (2006), 21662171

30. Bello CL, Smith E, Ruiz-Garcia A, et al.A phase I, open-label, mass balance study of $\left[{ }^{14} \mathrm{C}\right]$ dacomitinib (PF-00299804) in healthy male volunteers Cancer Chemother Pharmacol, 72 (2013),379385

31. Stopfer P, Marzin K, Narjes H, et al.Afatinib pharmacokinetics and metabolism after oral administration to healthy male volunteers Cancer Chemother Pharmacol, 69 (2012), pp. 1051-1061

32. Grande E, Harvey RD, You B, Batlle JF, Galbraith H, Sarantopoulos J, Ramalingam SS ${ }^{1}$, Mann $\mathrm{H}$, So K, Johnson M, Vishwanathan K. Pharmacokinetic Study of Osimertinib in Cancer Patients with Mild or Moderate Hepatic Impairment. J Pharmacol Exp Ther. 2019 May;369(2):291-299. doi: 10.1124/jpet.118.255919. Epub 2019 Mar 14

33.https://www.accessdata.fda.gov/drugsatfda_docs/label/2018/2 08065s008lbl.pdf

34. Kris MG, Camidge DR, Giaccone G, et al. Targeting HER2 aberrations as actionable drivers in lung cancers: phase II trial of the pan-HER tyrosine kinase inhibitor dacomitinib in patients with HER2-mutant or amplified tumors. Ann Oncol 2015;26:1421-7. 10.1093/annonc/mdv186

35. De Grève J, Moran T, Graas MP, et al. Phase II study of afatinib, an irreversible ErbB family blocker, in demographically and genotypically defined lung adenocarcinoma. Lung Cancer 2015;88:63-9. 10.1016/j.lungcan.2015.01.013

36. De Grève J, Teugels E, Geers C, et al. Clinical activity of afatinib (BIBW 2992) in patients with lung adenocarcinoma with mutations in the kinase domain of HER2/neu. Lung Cancer 2012;76:123-7. 10.1016/j.lungcan.2012.01.008

37. Park K, Tan EH, O’Byrne K, et al. Afatinib versus gefitinib as firstline treatment of patients with EGFR mutation-positive nonsmall-cell lung cancer (LUX-Lung 7): a phase IIB, open-label, randomised controlled trial. Lancet Oncol 2016;17:577-89. 10.1016/S1470-2045(16)30033-X

38. Wu YL, Cheng Y, Zhou X, et al. Dacomitinib versus gefitinib as first-line treatment for patients with EGFR-mutation-positive non-small-cell lung cancer (ARCHER 1050): a randomised, openlabel, phase 3 trial. Lancet Oncol 2017;18:1454-66. 10.1016/S1470-2045(17)30608-3

39. Cross DA, Ashton SE, Ghiorghiu S, et al. AZD9291, an irreversible EGFR TKI, overcomes T790M-mediated resistance to EGFR inhibitors in lung cancer. Cancer Discov 2014;4:1046-61. 10.1158/2159-8290.CD-14-0337

40.https://www.astrazeneca.com/media-centre/pressreleases/2019/tagrisso-significantly-improves-overall-survivalin-the-phase-iii-flaura-trial-for-1st-line-egfr-mutated-non-smallcell-lung-cancer-09082019.html 